\title{
Contract Translation from the Perspective of Text Typology
}

\author{
Yue Wu
}

Wuhan University of Science and Technology, Hubei, China

\author{
Keywords: Text Type; Contract Translation; Text Analysis; Translation Method
}

\begin{abstract}
This paper presents a study of contract translation from the perspective of text typology initiated by German linguist Reiss, and aims to conclude effective strategies of contract translation. The discussion is conducted based on the author has met during translation activities. It is found that contract translation method can be summarized into two words, "standardization", which means fixed forms and expressions, and "flexibility", which means reasonable adjustments.
\end{abstract}

\section{Introduction}

As a subcategory of legal text, contract differs from other text types and subtypes particularly in form, content and style. From the perspective of text type, contract belongs to informative text and its translation should use corresponding methods. In recently years, China's Belt and Road Initiative has facilitated external economic communication and there is an increasing need of contract translation. This paper presents a study of contract translation from English to Chinese based on Reiss' text typology, hoping to offer useful advice for such translation activities in the future.

\section{Text Types and Translation Methods}

Instead of accessing equivalence of translation at the micro level of word or sentence like before, Reiss (1971/2000) divides texts into three types as informative, expressive and operative in her book Translation Criticism: Potential and Limitations, and she also suggests corresponding translation methods for these three types.

Reiss (1977/1989) summarizes the main characteristics of each text type: informative text presents "plain communication of facts", expressive text features "creative composition", and operative text focuses on "inducing behavioral responses", and audio-medial text is added later by her to supplement the other three original types of text with audiovisual elements. Reiss (1971/2000) also points out that most texts have more than one function, but even this type of hybrid text has one primary function, and this decides which translation method to use.

Accordingly, Reiss puts forward three translation methods based on her initial text typology, which can be seen in the table below adapted by Munday (2001/2016).

Table 1 Functional characteristics of text types and links to translation methods

\begin{tabular}{|l|l|l|l|}
\hline Text type & Informative & Expressive & Operative \\
\hline Language function & $\begin{array}{l}\text { Informative } \\
\text { (representing objects } \\
\text { and facts) }\end{array}$ & $\begin{array}{l}\text { Expressive } \\
\text { (expressing sender's } \\
\text { attitude) }\end{array}$ & $\begin{array}{l}\text { Appellative (making } \\
\text { an appeal to text } \\
\text { receiver) }\end{array}$ \\
\hline Language dimension & Logical & Aesthetic & Dialogic \\
\hline Text focus & Content-focused & form-focused & Appellative-focused \\
\hline Target Text should ... & $\begin{array}{l}\text { Transmit referential } \\
\text { content }\end{array}$ & $\begin{array}{l}\text { Transmit aesthetic } \\
\text { form }\end{array}$ & Elicit desired response \\
Translation method & $\begin{array}{l}\text { "Plain prose", } \\
\text { explicitation as } \\
\text { required }\end{array}$ & $\begin{array}{l}\text { adopt perspective of } \\
\text { source text author }\end{array}$ & $\begin{array}{l}\text { "adaptive", equivalent } \\
\text { effect }\end{array}$ \\
\hline
\end{tabular}


The table relates language function, language dimension, text focus, goal of target text and corresponding translation method to those three types of text. Therefore, as the text type gets identified, these items are also determined. Therefore, for an expressive text such as a poem, its aesthetic form which expresses the poet's attitude is focused, and the target text should transmit such a form in the first place, using an "identifying method" to adopt perspective of the author of source text. And this is the common way of poem translation where translators do not focus on full equivalence of items but the form, rhymes and thoughts and feelings.

Despite criticisms arise from the deficiency of Reiss' categorization of text types in differentiating text subtypes, it is truly important for a translator to decide what type of text it belongs to in the first place, so the translator can choose the best translation methods to reproduce a counterpart in the target language that matches up with the source text to the largest extent. Zhang (2013) affirms that text typology provides a theoretical frame for evaluating text function, and translators should formulate translation methods and target texts based on both text function and translation purpose.

\section{Text Analysis of Contract}

Type and Method. Contract is a kind of legal document that stipulates rights and obligations of two or more parties. According to the category of text type by Reiss, the source text of contract falls into the informative type, as its content dominates over other elements where readers desire to know rights and obligations of parties concerned under the contract. Moreover, as Bhatia (1997) points out that genre analysis is crucial to the realization of translation purpose, contract differs from other informative texts in its compulsory attitude towards the parties concerned expressed through its characteristic wording. Therefore, the target text must accurately and completely convey the ideas of the source text, and it should adopt fixed expressions of target audience to ensure its readability.

Since we have identified the contract is an informative text, we should adopt corresponding translation method, that is, as Reiss concludes, to use "plain prose" and achieve required explicitation. Although this principle is rather rough, it guides the author's translation process and contributes to specific strategies and techniques below. For example, Su (2014) adopts the idea of text typology and proposes four principles of legal translation, which are organized structure, clear language, logical writing and required format. As contract concerns with both legal English and specific background knowledge, it is noted that adequate importance should be attached to terminology and jargons.

Comparison of English and Chinese Contracts. English and Chinese contracts have both similarities and differences.

The first similarity is at the level of text. It is easy to notice that contracts, either in English or Chinese, use an orderly form that basically divides into several parts, including the preface, the main body (sections, articles, clauses and sub-clauses), the closure and the annexes, where a parallel structure with serial numbers is frequently used.

Then speaking of sentence, both English and Chinese contracts contain declarative, imperative and conditional sentences to stipulate what to do and what not to do, what is allowed and what is forbidden. 
Table 2 Daily English and Literary English with Chinese Pinyin [Adapted from Chen (2010)]

\begin{tabular}{|c|c|c|}
\hline Daily Word & Literary Word & Chinese (Pinyin) \\
\hline end & terminate & zhōng zhǐ \\
\hline make out & formulate & zhì dìng \\
\hline if & provided that & rú rù̀ \\
\hline cancel & rescind & chè xiāo \\
\hline considering & whereas & jiàn yú \\
\hline obey & abide by & zūn xún \\
\hline by which & whereby & yóu cì \\
\hline
\end{tabular}

As for the word level, the language used in contract is very formal and the wording greatly involve archaic words and relevant terminology of certain fields or industries. Table 2 lists some common words used in contracts.

There are differences between English and Chinese contracts as well. Most differences between English contracts and Chinese ones lie in primary differences arising from distinct lingual conventions. Wu (2011) concludes major stylistics differences between English and Chinese business contracts.

Concerning the properties of words in English and Chinese contracts, nominalization is a salient feature in formal English, which is true of contract as well. In contrast, Chinese contract prefers to use verb which is used quite frequently.

Another difference is also linguistic but at the sentence level. Although English and Chinese contracts both use certain sentence patterns as we mentioned above, it is obvious that English contracts use long sentences instead of short ones commonly seen in Chinese contracts. Meanwhile, in English, important information is given before supportive details, which is just reversed in Chinese, and this leads to different positions of attributes and adverbials, that is, they follow central words in English but precede in Chinese.

\section{Adapted Translation Strategy and Technique}

From the perspective of text type, English-Chinese contract translation should take explicitation as the keynote by using plain prose. This is the general guidance. To be more specific, the author tries to promote two supplementary strategies based on both similarities and differences between English and Chinese contracts, which are detailed below respectively with concrete techniques.

Standardization. Since English and Chinese contracts have some similarities, whose translation has developed a relatively fixed style, we can generally preserve the original features of the source text.

First of all, the form and structure of terms and conditions can be maintained because they are the same both in English and Chinese. Yet the usages of serial numbers should be taken into account and necessarily adjusted. For example, we can maintain "1", "2", and " 3 " as they are also frequently used in Chinese, but it is better to replace "I", "II", "III" with corresponding Chinese characters that indicate the sequence.

Second, there are many archaic words in English contract, such as "hereby", "therein", and "whereof". When translating these words, it is better to use Chinese counterparts of the same stylistic feature, such as "jù cî", "qí zhōng", which are similarly concise, accurate and formal in Chinese.

Third, English contracts use such modal verbs as "shall", "must", "may" to show an regulative attitude or conditionality. Li (2007) discusses their functions and translations, and concludes that 
"shall" can be translated into "xū", "yīng", "yīng dāng" or zero-translated as it depends, "must" can be translated as "bì xū", and "may" as "kě". These translations are widely acknowledged in contract translation in China and can be directly used.

Similarly, for those phrases frequently used in English contracts, such as "if and only if", "unless and until", "as appropriate" and "including but not limited to", there have been conventional expressions in Chinese to exactly convey the same meanings. These paired words can adopt their fixed translations.

Flexibility. In contrast to "fixation", "flexibility" is a strategy mainly based on the linguistic differences between English and Chinese contracts. This is largely related to the primary differences between English and Chinese lingual expressions, basically including some common translation techniques summed up by previous translators allowing the target text to perform its informative function with more readable and fluent language.

The most frequent adjustment is about word order. In English, the position of adverbial is very flexible, while in Chinese, it usually precedes the main clause. Here is an example.

e.g. 1 Each item of Plant and Materials, to the extent consistent with the Laws of the Country, shall become the property of the Employer at whichever is the earlier of the following times, free from liens and other encumbrances:

When translating the sentence above into Chinese, we must move the conditional adverbial "to the extent consistent with the Laws of the Country" to the very beginning of the whole sentence, and likewise, place "at whichever if the earlier of the following items" before the verb "become".

Another big difference between English and Chinese is their use of logical words. In English, a pair of logical words such as "because" and "so", "though" and "but" cannot be used at the same time; however, in Chinese, especially in written form, it is important to ensure "yīn wéi (because)" and "suǒ yǐ (so)" together to clearly indicate the logical relation so as to avoid ambiguity in the case of many short sentences.

As we mentioned above, English contracts use long sentences while Chinese contracts prefers relatively short expressions. See the example below.

e.g. 2 The Contractor shall indemnify the Employer for any liability arising from the Contractor's failure to export the Contractor's Equipment following the completion of the performance of the Contractor's obligations under this Contract.

This sentence contains 32 English words without any punctuation. If we put it in Chinese without punctuation, it will make readers puzzled and waste their time, so we should split the long sentence into several to express its ideas in an explicit and user-friendly way.

To sum up, "flexibility" means target-text-oriented adjustments in the general principle of information-focused translation. When conveying the information carried by the source text, the translator should use common expressions in the target language on the basis of accurate informative transmission.

\section{Conclusion}

Text typology which is initially proposed by Reiss and later developed by other scholars is deemed as "a great influence and contribution to the modern translation theory" (Chesteman, 1989:15). It guides us to conduct text analysis before getting down to translation. Different text types should adopt different translation methods. For translating English contracts into Chinese, or vice versa, we can combine "fixation", which is based on their similarities, with "flexibility", which is based on their differences, to produce an equally informative and readable target text.

However, as contracts vary in subjects, contents and even customs in different regions, and informative texts are of a wide range, the efforts of this paper are somewhat limited. Whether these strategies and techniques developed from the perspective of text type are applicable to other informative texts has to be thought through. 


\section{References}

[1] A. Chesterman, ed. Readings in translation theory [M]. Oy Finn Lectura Ab, 1989.

[2] J. Munday. Introducing translation studies: Theories and applications [M]. Routledge, 2016.

[3] K. Reiss. Text types, translation types and translation assessment [J]. Readings in translation theory, 1989: 105-15.

[4] K. Reiss. Translation Criticism: The Potentials and Limitations: Categories and Criteria for Translation Quality Assessment [M]. Manchester, U.K.: St. Jerome Pub., 2000.

[5] V. K. Bhatia. Translating Legal Genres [A]. Text typology and translation [C]. Trosborg, Anna, ed. Vol. 26. John Benjamins Publishing, 1997.

[6] H. H. Wu. Study on Differences of Stylistic Features between English and Chinese Business Contracts and their Revelation to Translating Methods [J]. Journal of Changesha University of Science \& Technology (Social Science) 2011, 26(5): 121-124.

[7] J. P. Chen. A Study of Business English [M]. Hangzhou: Zhejiang University Press.

[8] K. X. Li. Functions of Modal Verbs in Legal Documents and Their Translation [J]. Chinese Translators Journal, 2007(06): 54-60.

[9] M. F. Zhang. Text Type, Translation Purpose and Translation Strategy [J]. Shanghai Journal of Translators, 2013(4): 5-10.

[10] W. Su. The Types of Text and Translation [J]. Journal of Hebei United University (Social Science Edition), 2014, 14(01): 168-170. 